\title{
RSP Revisitada Ciências e arte de educar
}

Texto publicado na RSP de março de 1957 (vol. 74, ano 20, n.3)

Agradeço ao amigo - e mestre - Professor Fernando de Azevedo, o privilégio de vos falar, ao encerrar-se êste seminário de educação, com o qual se inauguraram, em 1957, as atividades do Centro Regional de Pesquisas Educacionais, confiado, afortunadamente, à sua alta e sábia direção.

Este centro, como os seus congêneres, o brasileiro e os demais centros regionais, representam elos no esfôrço continuado com que o Brasil tem procurado acompanhar o desenvolvimento da arte de educar - a educação nos últimos cinqüenta anos, desenvolvimento que se caracteriza por uma revisão de conceitos e de técnicas de estudo, à maneira, dir-se-ia, da transformação operada na arte de curar - a medicina quando se emancipou da tradição, do acidente, da simples "intuição" e do empirismo e se fêz, como ainda se vem fazendo, cada vez mais científica.

Todos sabemos que isto se deu com a medicina, devido aos progressos dos métodos de investigação e de prova. O desenvolvimento das ciências que lhe 
iam servir de base e das técnicas científicas de que iria cada vez mais utilizar-se e mesmo apropriar-se, levaram a medicina a um progresso crescente, com a aplicação cada vez mais consciente de métodos próprios de investigação e de prova. São dêsse tipo - claro que sob os influxos dos progressos mais recentes ainda de outras ciências - os desenvolvimentos que desejamos suscitar na educação, com o cultivo, nos centros de pesquisas, que se estão fundando no Brasil, dentre os quais êste de São Paulo é o mais expressivo, de métodos próprios de investigação e prova no campo educacional.

Como a medicina, a educação é uma arte. E arte é algo de muito mais complexo e de muito mais completo que uma ciência. Convém, portanto, deixar quanto possível claro de que modo as artes se podem fazer científicas.

Arte consiste em modos de fazer. Modos de fazer implicam no conhecimento da matéria com que se está lidando, em métodos de operar com ela e em um estilo pessoal de exercer a atividade artística. Nas belas artes, ao estilo pessoal chegamos a atribuir tamanha importância que, muitas vêzes, exagerando, consideramos que a personalidade artística é tudo que é necessário e suficiente para produzir arte. Não é verdade. Mesmo nas belas artes, o domínio do conhecimento e o domínio das técnicas, se por si não bastam, são, contudo, imprescindíveis à obra artística.

A educação pode, com alguns raros expoentes, atingir o nível das belas artes, mas, em sua generalidade, quase sempre, não chega a essa perfeição, conservandose no nível das artes mecânicas ou práticas, entendidos os termos no sentido humano e não no sentido de maquinal, restritivo apenas quanto a belo e estético.

O progresso nas artes - sejam belas ou mecânicas - se fará um progresso científico, na medida em que os métodos de estudo e investigação para êste progresso se inspirem naquelas mesmas regras que fizeram e hão de manter o progresso no campo das ciências, ou sejam as regras, para usar expressão que não mais se precisa definir, do "método científico".

A passagem, no campo dos conhecimentos humanos, do empirismo para a ciência foi e é uma mudança de métodos de estudo, graças à qual passamos a observar e descobrir de modo que outros possam repetir o que observarmos e, descobrirmos e, assim, confirmar os nossos achados, que se irão, de tal maneira, acumulando e levando a novas buscas e novas descobertas. Se esta foi a mudança que originou os corpos sistematizados de conhecimentos a que chamamos de ciências, um outro movimento, paralelo ao das ciências e dêle conseqüente mas, de certo modo autônomo, foi o da mudança das "práticas" humanas pela aplicação do conhecimento científico. Ao conhecimento empírico correspondiam as práticas empíricas ao conhecimento científico passaram a corresponder as práticas científicas. As práticas, com efeito, fundadas na que a ciência observou, descobriu e acumulou, e, por seu turno, obedecendo aos mesmos métodos científicos, se transformaram em prática tecnológicas e, dêste modo renovadas, elas próprias se constituíram em fontes novos problemas, novas buscas e novos progressos.

Com o desenvolvimento das ciências físicas e matemáticas e depois das ciências biológicas, as artes da engenharia e da medicina, obedecendo em suas "práticas" às regras científicas da observação, da descoberta e da prova puderam frutificar nos espantosos progressos modernos. Algo de semelhante é que se terá de introduzir na arte de educar, a fim de se lhe darem as 
condições de desenvolvimento inteligente, controlado, contínuo e sistemático, que caracterizam o progresso científico.

Não se trata, pois, de criar propriamente uma "ciência da educação", que, no sentido restrito do têrmo, como ciência autônoma, não existe nem poderá existir; mas de dar condições científicas à atividade educacional, nos seus três aspectos fundamentais - de seleção de material para o currículo, de métodos de ensino e disciplina, e de organização e administração das escolas. Por outras palavras: trata-se de levar a educação para o campo das grandes artes já científicas - como a engenharia e a medicina - e de dar aos seus 'métodos, processos e materiais a segurança inteligente, a eficácia controlada e a capacidade de progresso já asseguradas às suas predecessoras relativamente menos complexas.

Está claro que essa inteligência da arte de educar a afasta radicalmente das artes predominantemente formais, como a do direito, por exemplo, à qual, me parece, temos, como país, uma irresistível inclinação a identificar a educação. Com efeito, embora não caiba aqui a análise aprofundada dessa inclinação, os sinais são muito evidentes de que ainda consideramos educar antes como uma arte dominantemente formal, à maneira do direito ${ }^{1}$, do que como uma arte material, à maneira da medicina ou da engenharia.

Fora essa tendência distorciva, mais entranhada quiçá do que o imaginamos e que importa evitar, a introdução de métodos científicos no estudo da educação não irá determinar nada de imediatamente revolucionário. As artes sempre progrediram. Mas, antes do método científico, progrediram por tradição, por acidente, pela pressão de certas influências e pelo poder "criador" dos artistas. Com o método científico, vamos submeter as "tradições" ou as chamadas "escolas" ao crivo do estudo objetivo, os acidentes às investigações e verificações confirmadoras e o poder criador do artista às análises reveladoras dos seus segredos, para a multiplicação de suas descobertas; ou seja, vamos examinar rotinas e variações progressivas, ordenálas, sistematizá-las e promover, deliberadamente, o desenvolvimento contínuo e cumulativo da arte de educar.

Não se diga, entretanto, que tenha sido sempre êste o entendimento do que se vem chamando de ciência da educação, à qual já aludimos com as devidas reservas. Pelo contrário, o que assistimos nas primeiras décadas dêste século e que só ultimamente se vem procurando corrigir foi a aplicação precipitada ao processo educativo de experiências científicas que poderiam ter sido psicológicas, ou sociológicas, mas não eram educacionais, nem haviam sido devidamente transformadas ou elaboradas para a aplicação educacional.

De outro lado, tomaram-se de empréstimo técnicas de medida e experiência das ciências físicas e se pretendeu aplicá-las aos fenômenos psicológicos e mentais, julgando-se científicos os resultados porque as técnicas - tomadas de empréstimo - eram científicas e podiam os tais resultados serem formulados quantitativamente.

Houve, assim, precipitação em aplicar diretamente na escola "conhecimentos" isolados de psicologia ou sociologia e, além disto, precipitação em considerar êsses "conhecimentos" verdadeiros conhecimentos.

A realidade é que não há ciência enquanto não houver um corpo sistemático de conhecimentos, baseados em princípios e leis gerais, que lhes dêem coerência e eficácia. Aí estão as ciências matemáticas e físicas com todo o seu lento 
evoluir até que pudessem florescer nas grandes áreas das tecnologias, que correspondem à sua aplicação às práticas humanas. Logo após vem o ainda mais lento progresso das ciências biológicas e a agronomia, a veterinária e a medicina como campos de aplicação tecnológica.

Para que as "práticas" educativas possam também beneficiar-se de progresso semelhante, será preciso antes de tudo que as ciências que lhes irão servir de fontes se desenvolvam e ganhem a maturidade das grandes ciências já organizadas. Até aí há que aceitar não só que o progresso seja lento, mas que seja algo incerto e, sobretudo, não susceptível de generalização. Mas antes progredir, assim, tateando, sentindo os problemas em tôda a sua complexidade, mantendo em suspenso os julgamentos, do que julgar que podemos simplificar a situação, considerá-la puramente física ou biológica e aplicar métodos e técnicas aceitáveis para tais campos, mas inadequadas para o campo educativo, pela sua amplitude e complexidade.

Convém, realmente, insistir na distinção entre o campo da ciência e do conhecimento em si e o campo da aplicação do conhecimento e da prática ou da arte. Bastaria, talvez, dizer que a ciência é abstrata, isto é, que busca conhecer o seu objeto num sistema tão amplo de relações, que o conhecimento científico, como tal, desborda de qualquer sistema particular, para se integrar num sistema tão geral, que nele só contam as relações dos conhecimentos entre si; e que a "prática" é um sistema concreto e limitado, em que aquêles conhecimentos se aplicam com as modificações, alterações e transformações necessárias à situação. Por isto mesmo, uma regra de arte, ou seja, uma regra de prática.

Leis e fatos, que são os produtos das ciências, ministram ao prático não propriamente regras de operação, mas, recursos intelectuais para melhor observar e melhor guiar a sua ação no campo mais vasto, mais complexo, com maior número de variáveis da sua indústria ou da sua arte. A velha expressão, na prática é diferente, é um modo simples de indicar essa verdade essencial de que a ciência é um recurso indireto, é um intermediário e nunca uma regra direta de ação e de arte. A ciência é uma condição - e mesmo uma condição básica - para a descoberta tecnológica ou artística, mas não é, ou ainda não é essa descoberta. Quando se trata de tecnologia das ciências físicas, o processo prático não chega à exatidão do processo de laboratório, mas, pode chegar a graus apreciáveis de precisão. Mas, se a tecnologia é a de um processo de educação, podemos bem imaginar quanto as condições de laboratório são realmente impossíveis de transplantação para a situação infinitamente mais complexa da atividade educativa.

Não quer isto dizer que a ciência seja inútil, mas que a sua aplicação exige cuidados e atenções todo especiais, valendo o conhecimento científico como um ingrediente a ser levado em conta, sem perder, porém, de vista todos os demais fatôres.

Em educação muita cousa se fêz em oposição a êsse princípio tão óbvio, com a aplicação precipitada de conhecimentos científicos ou supostamente científicos diretamente como regras de prática educativa e a transplantação de técnicas quantitativas das ciências físicas para os processos mentais, quando não educativos, importando tudo isto em certo descrédito da própria ciência.

Para tal situação concorreu, sem dúvida, o fato de nem sempre haverem sido as "práticas educativas" as fornecedoras dos "dados" do problema, como 
deverá ser, se tivermos de contar com a ciência para nos ajudar a progredir na arte de educar, E em segundo lugar, concorre certa impaciência de resultados positivos que aflige tanto - bélas! - as ciências jovens que servem de fonte e base a uma possível arte de educar menos empírica e mais científica.

Com efeito, tais ciências não nos irão dar regras de arte, mas conhecimentos intelectuais para rever e reconstruir, com mais inteligência e maior segurança, as nossas atuais regras de arte, criar, se possível, outras e progredir em nossas práticas educacionais, isto é, nas práticas mais complexas da mais complexa arte humana.

Tudo, na realidade, entra nessa prática. A nossa filosofia, concebida como o conjunto de valores e aspirações, as ciências biológicas, psicológicas e sociais, tôdas as demais ciências como conteúdo do ensino, enfim, a cultura, a civilização e o pensamento humano em seus métodos e em seus resultados. Prática desta natureza e desta amplitude não vai buscar as suas regras em nenhuma ciência isolada, seja mesmo a psicologia, a antropologia, ou a sociologia; mas em todo o saber humano e, por isto mesmo, será sempre uma arte em que todas as aplicações técnicas terão de ser transformadas, imaginativa e criadoramente, em algo de plástico e sensível susceptíveis de ser considerado antes sabedoria do que saber - opostos tais termos um ao outro no sentido de que sabedoria é, antes de tudo, a subordinação do saber ao interesse humano e não próprio interesse do saber pelo saber (ciência) e muito menos a interesses apenas parciais ou de certos grupos humanos.

Mas tôda essa dificuldade não é para que o educador se entregue à rotina, ao acidente ou ao capricho, mas busque cooperar na transição da educação do seu atual empirismo para um estado progressivamente científico.

Dois problemas diversos avultam nessa transição. Primeiro, é o do desenvolvimento das ciências fonte da educação. Assim como as ciências matemáticas e físicas são as ciências fonte principais da engenharia, assim como, as ciências biológicas são as ciências fonte principais da medicina, assim a psicologia, a antropologia e a sociologia são as ciências fonte principais da educação.

Enquanto estas últimas não se desenvolverem até um mais alto grau de maturidade e segurança não poderão dar à educação os elementos intelectuais necessários para a elaboração de técnicas e processos que possam constituir o conteúdo de uma possível "ciência de educação". E êste é o segundo problema. Porque ainda que as ciências fonte quanto à educação estivessem completamente desenvolvidas, nem por isto teríamos automaticamente a educação renovada cientificamente, pois, conforme vimos, nenhuma conclusão científica é diretamente transformável em regra operatória no processo de educação. Todo um outro trabalho tem de ser feito para que os fatos, princípios e leis descobertas pela ciência possam ser aplicadas na prática educacional.

$\mathrm{Na}$ própria medicina, com efeito, atrevo-me a afirmar, os princípios e leis da ciência servem antes para guiar e iluminar a observação, o diagnóstico e a terapêutica, não se impondo rigidamente como regras à arte médica, regras de clínica, regras imperativas da arte de curar.

A ciência oferece, assim, a possibilidade de um primeiro desenvolvimento tecnológico, que fornece à arte melhores recursos para a investigação dos seus próprios problemas e, dêste modo, sua melhor solução. Num segundo desenvolvimento 
também tecnológico, oferece recursos novos para o tratamento e a cura, mas a arte clínica continua sendo uma arte de certo modo autônoma, a ser aprendida à parte, envolvendo métodos próprios de investigação e análise, de registro dos casos, de comparações e analogias, de experiência e tirocínio, em que, além de um conteúdo próprio mais amplo do que os puros fatos científicos, sobressaem sempre o estilo pessoal do médico, a sua originalidade e o seu poder criador. A ciência, aliás, longe de mecanizar o artista ou o profissional, arma a sua imaginação com os instrumentos e recursos necessários para seus maiores vôos e audácias.

Ora, o mesmo é o que há de ocorrer no domínio da educação - da arte de educar. Neste, o campo precípuo ou específico - atelier, laboratório ou oficina é a sala de classe, onde os mestres, eles próprios também investigadores, desde o jardim de infância até a universidade. São as escolas o campo de ação dos educadores, como o dos médicos são os hospitais e as clínicas.

Os especialistas de ciências autônomas são grandes contribuintes para a chamada ciência médica, como serão para a que vier a se chamar de ciêcia da educação, mas nenhum resultado científico, isto é, o conhecimento de cada ciência, mesmo ciência básica ou ciência fonte, é por si um conhecimento educacional ou médico, nem dará diretamente uma regra de ação médica ou educacional. Tais conhecimentos ajudarão o médico ou o educador a observar melhor, a diagnosticar melhor e, assim, a elaborar uma melhor arte de curar ou uma melhor arte de educar.

Tomemos uma ilustração qualquer. Sejam, por exemplo, os testes de inteligência, que se constituíram, por certo, um dos mais destacados recursos novos da "ciência" para a técnica escolar. Para que servem êles? - Para diagnosticar com maior segurança limites de capacidade de aprender do aluno. Se o tomarmos apenas para isto, aumentaremos sem dúvida os nossos recursos de observação e conhecimento do aluno e melhor poderemos lidar com as situações de aprendizagem, sem perder de vista as demais condições e fatôres de tais situações.

Se, porém, ao contrário, tomarmos êsse recurso parcial de diagnóstico mental como uma regra educativa e quisermos homogeneizar rigidamente os grupos de Q.I. idêntico ou aproximado e proceder uniformemente com todos os seus componentes, não estaremos obedecendo à complexidade total da situação prática educativa e muito menos a nenhuma "ciência de educação", pois esta não reconheceria tal classificação como válida, reconhecendo hoje que a situação é totalmente empírica, incluindo fatôres entre os quais o Q.I. é apenas um no complexo da situação "aluno-professor-grupo-meio" em que se encontra o aprendiz.

Nem por isto será, entretanto, inútil o conhecimento do Q.I., pois a alteração da capacidade de aprender do aluno passa, em face dos dados do Q. I., a ser vista e estudada sob outra luz.

A ciência, assim, como já afirmamos, não oferece sinão um dado básico e jamais a regra final de operação. Esta há que ser descoberta no complexo da situação de prática educativa, em que se encontrem professor e aluno, levando-se em conta todos os conhecimentos científicos existentes, mas, agindo-se autônomamente à luz dos resultados educativos propriamente ditos, isto é, de formação e progresso humano do indivíduo, a que visam tanto aquêles conhecimentos quanto êstes resultados. 
Nesta fase é que vimos entrando ultimamente. Há um real amadurecimento entre as ciências especiais, fontes da educação, superados os entusiasmos das primeiras desccobertas. Com relação aos testes de inteligência, até o nome vem sendo hoje evitado, preferindo-se o nome de testes de aptidões diferenciais, pois já se reconhece que estamos longe de medir o famoso "g" ou fator geral, mas medimos apenas uma série de aptidões decorrentes da cultura em que se acha imersa a criança e não inteiramente independente da educação anterior. Não é isto nenhum descrédito para os testes chamados de inteligência, mas pelo contrário, um progresso, uma nova precisão.

Prejudicial, talvez, foi antes o excessivo entusiasmo anterior. A precipitada aplicação de produtos ainda incertos de "ciência" à escola parece haver exacerbado certos aspectos quantitativos e mecanizantes, conduzindo ao tratamento do aluno como algo abstrato a ser manipulado por critérios de classificação em grupos supostamente homogêneos, dando ao professor a falsa esperança de poder ensinar por meio de receitas, muitas das quais de científicas só tinham a etiqueta.

Com relação à "ciência" do ato de aprendizagem o mesmo novo desenvolvimento se pode observar. Compreende-se melhor que "aprender" é algo de muito mais complexo do que se poderia supor e francamente uma atividade prática a ser governada, se possível, por uma psicotécnica amadurecida e não pela psicologia. Ora, quanto isto nos distancia das "leis" de aprendizagem, em que se ignoravam, além de muito mais, as relações professoraluno-colegas e se imaginava o aprendiz como um ser isolado e especial, que operasse abstratamente, como abstratas haviam sido e não podiam deixar de ser as experiências de laboratório que haviam conduzido às supostas leis de aprendizagem.

Para essa precipitada aplicação na escola de resultados fragmentários e imaturos da ciência, concorreu também e merece isto registro especial - uma peculiar prevenção, digamos assim, da ciência para com a filosofia, ou um dissídio entre uma e outra, de alcance e efeito negativo. Explico o que desejo significar.

Como tôda ciência foi primeiro filosofia e como seu progresso geralmente se processou com o distanciamento cada vez maior daquela filosofia originária, pode parecer e parece que ciência e filosofia se opõem e os conhecimentos serão tanto mais científicos quanto menos filosóficos.

Ora, tal êrro é grave, mesmo em domínios como os da matemática e da física. Mas em educação é bem mais grave. Com efeito, se històricamente, progresso das ciências se fêz com o seu distanciamento dos métodos puramente dedutivos da filosofia, não quer isto dizer que as ciências não operem realmente sôbre uma filosofia. O seu afastamento foi antes um afastamento de determinada filosofia exclusivamente especulativa, ou melhor, "livremente" especulativa, para a adesão a uma nova filosofia de base científica; como esta nova filosofia foi quase sempre uma filosofia implícita e não explícita, o equívoco pôde se estabelecer e durar.

A realidade é que filosofia e ciência são dois pólos do conhecimento humano, a filosofia representando o mais alto grau de conhecimento geral e a ciência tendendo para o mais alto grau de conhecimento especial. Entre ambas tem de existir um comércio permanente, a ciência se revendo à luz dos pressupostos e conceitos generalizadores da filosofia. Neste sentido, a filosofia nutre permanentemente a ciência 
com as suas integrações e visões de conjunto e a ciência nutre a filosofia, forçando-a a combinações e síntese mais fundadas, menos inseguras e mais ricas.

Não se trata do quase equívoco de que a filosofia elabora os fins e a ciência os meios, mas da verdade de que ambas elaboram, criticam e refinam os fins e os meios, pois uns e outros sofrem e precisam sofrer tais processos de crítica e revisão, a ciência criando muitas vezes novos fins com as suas descobertas e a filosofia criticando permanentemente os meios à luz dos fins que lhe caiba descobrir e propor à investigação científica.

A não existência dessa cooperação ou interação, entre a ciência e a filosofia, levou a chamada "ciência da educação" a não ter filosofia, o que corresponde realmente a aceitar a filosofia do statu quo e a trabalhar no sentido da tradição escolar, a que efetivamente obedeceu, agravando, em muitos casos, com a eficiencia nova que lhes veio trazer, os aspectos quantitativos e mecânicos da escola, que lhe teriam de parecer - et pour cause - os mais científicos aspectos da escola.

Hoje, felizmente, estamos bem mais amadurecidos e os estudos de educação não desdenham das contribuições que lhes terá de trazer a filosofia, também ela cada vez mais de base científica, e começam a ser feitos à luz da situação global escolar e de suas "práticas", que urge rever e tornar progressivas em face dos conhecimentos que vimos adquirindo no campo das ciências especiais, ciências fonte da educação principalmente a antropologia, a psicologia é a sociologia não já para aplicar na escola, diretamente, os resultados da investigação científica no campo destas ciências, mas para, tarnando tais resultados como instrumentos intelectuais, elaborar técnicas, processos e modos de operação aprcpriados à função prática de educação.

'Os nossos Centros de Pesquisa Educacional se organizam, assim, num momento de revisão e tomada de consciência dos progressos do tratamento científico da função educativa e, por isto mesmo, têm certa originalidade. Pela primeira vez, busca-se aproximar uns dos outros os trabalhadores das ciências especiais, fontes de uma possível "ciência" da educação, e os trabalhadores de educação, ou sejam os dessa possível "ciência" aplicada da educação. Esta aproximação visa, antes de tudo, levar o cientista especial, o psicólogo, o antropólogo, o sociólogo, a buscar no campo da "prática escolar" os seus problemas. Note-se que os problemas das ciências biológicas humanas originaram- se e ainda hoje se originam na medicina.

É preciso que as ciências sociais, além de outros problemas que lhe sejam expressamente próprios, busquem nas atuais situações de prática educativa vários e não poucos problemas, que também lhe são próprios.

Como na medicina, ou na engenharia, não há, strictu-senso, uma ciência de curar nem de construir, mas, artes de curar e de construir, fundadas em conhecimentos de várias ciências, assim os problemas da arte de educar, quando constituírem problemas de psicologia, de sociologia e de antropologia, serão estudados por essas ciências especiais e as soluções encontradas irão ajudar o educador a melhorar a sua arte e, dêste modo, provar o acêrto final daquelas soluções ou conhecimentos, ou, em caso contrário, obrigar o especialista a novos estudos ou a nova colocação do problema. A originalidade dos Centros está em sublinhar especialmente essa nova relação entre o cientista social e o educador. Até ontem o educador julgava dispor de 
uma ciência autônoma, por meio da qual iria criar simultâneamente um conhecimento educacional e uma arte educacional. E o cientista social estudava outros problemas e nada tinha diretamente a ver com a educação. Quando resolvia cooperar com o educador, despia-se de sua qualidade de cientista e se fazia também educador.

Os Centros vêm tentar associá-los em uma obra conjunta, porém com uma perfeita distinção de campos de ação. $\mathrm{O}$ sociólogo, o antropólogo e o psicólogo social não são sociólogos-educacionais, ou antropólogo-educacionais, ou psicólogoseducacionais, mas sociólogos, antropólogos e psicólogos estudando problemas de sua especialidade, embora originários das "práticas educacionais".

Os educadores - sejam professôres, especialistas de currículo, de métodos ou de disciplina, ou sejam administradores não são, repitamos, cientistas, mas, artistas, profissionais, práticos (no sentido do practioner inglês), exercendo, em métodos e técnicas tão científicas quanto possível, a sua grande arte, o seu grande ministério. Serão cientistas como são cientistas os clínicos; mas sabemos que só em linguagem lata podemos efetivamente chamar os clínicos de cientistas.

Acreditamos que esse encontro entre cientistas sociais e educadores "científicos" - usemos o termo - será da maior fertilidade e, sobretudo, que evitará os equívocos ainda tão recentes da aplicação precipitada de certos resultados de pesquisas científicas nas escolas, sem levar em conta o caráter próprio da obra educativa. Com os dados que lhe fornecerá a escola, o cientista irá colocar o problema muito mais acertadamente e submeter os resultados à prova da prática escolar, aceitando com maior compreensão êste teste final.
Tenho confiança de que bem esclarecida e estudada essa posição, de que estou a tentar aqui os fundamentos teóricos, ser-nos-á possível ver surgir o sociólogo estudioso da escola, o antropólogo estudioso da escola, o psicólogo estudioso do escolar, não já como êsses híbridos que são, tantas vêzes, os psicólogos, sociólogos e antropologistas educacionais, nem bem cientistas nem cientistas nem bem cientistas nem também educadores, mas como cientistas especializados, fazendo, verdadeiramente, ciência, isto é, socologia, antropologia e psicologia, e ajudado os educadores, ou sejam os clínicos da educação, assim os cientistas da biologia ajudam os clínicos da medicina.

Parece-me não ser uma simples nuance a distinção. Por outro lado, isto é o que já se faz, sempre que se distingue o conhecimento teórico, objeto da ciência, da regra prática, produto da tecnologia e da arte. A confusão entre os dois campos é que é prejudicial. É preciso que o cientista trabalhe com o desprendimento e o "desinterêsse" do cientista, que não se julgue êle um educador espicaçado em resolver problemas práticas, mas o investigador que vai pesquisar pelo interêsse da pesquisa. O seu problema orginou-se de uma situação de prática educacional, mas é um problema de ciência, no sentido de estar desligado de qualquer interêsse imediato e visar estabelecer uma teoria, isto é, o problema é um problema abstrato, pois, abstração é essencial para o estudo científico que vise a formulação de princípio e leis de um sistema coerente e integrado de relações. Os chamados estudos "desinteressados" ou "puros" não são mais do que isto. São estudos das cousas em si mesmas, isto é, nas suas mais amplas relações possíveis. As teorias científicas do calor, da luz, da côr ou da eletricidade são 
resultados do estudo dêsses fenômenos em si mesmos, desligados de qualquer interesse ou uso imediato. No fim de contas, a teoria é, como se diz, a mais prática das cousas, porque, tendo sido o resultado do estudo das cousas no aspecto mais geral possível, acaba por se tornar de utilidade universal.

Assim terão de ser e nem poderão deixar de ser os estudos dos cientistas sociais destinados a contribuir para o progresso das práticas educativas, pois, do contrário, estariam os cientistas aplicando conhecimentos, e não buscando descobrilos. Armados que sejam os problemas, originários da prática educacional, mas não de prática educacional, deve o pesquisador despreocupar-se de qualquer interêsse imediato e alargar os seus estudos até os mais amplos limites, visando descobrir os "fatos" e as suas relações, dentro dos mais amplos contextos, para a eventual formulação dos "princípios" e "leis" que os rejam.

Tais “fatos", princípios e "leis" não irão, porém, fornecer ao educador, repitamos, nenhuma refra de ação ou de prática, mas, idéias, conceitos, instrumentos intelectuais para lidar com a experiência educacional em sua complexidade e variedade e permitir-lhe a elaborar, por sua vez, as técnicas flexíveis e elásticas de operação e os modos de proceder inteligentes e plásticos, indispensáveis à condução da difícil e suprema arte educar.

Cientistas e educadores trabalharão juntos, mas, uns e outros, respeitando o campo de ação de cada um dos respectivos grupos profissionais e mutuamente se auxiliando na obra comum de descobrir o conhecimento e descobrir as possibilidades de sua aplicação. O método geral de ação de uns e outros será o mesmo, isto é, o "método científico" e, nesse sentido, é que todos se podem considerar homens de ciência. O educador, efeito, estudando e resolvendo os problemas da prática educacional, obedecerá às regras do método científico, do mesmo modo que o médica resolve, com disciplina científica, os problemas práticos da medicina: observando com inteligência e precisão, registrando essas observações, descrevendo os procedimentos seguidos e os resultados obtidos, para que possam ser apreciados por outrem e repetidos, confirmados ou negados, de modo que a sua própria prática da medicina se faça também pesquisa e os resultados se acumulem e multipliquem.

Os registros escolares de professôres e administradores, as fichas de alunos, as histórias de casos educativos, ou descrições de situações e de pessoas constituirão o estoque, sempre em crescimento, de dados, devidamente observados e anotados, que irão permitir o desenvolvimento das práticas educacionais e, conforme já dissemos, suscitar os problemas para os cientistas, que aí escolherão aquêles susceptíveis de tratamento científico, para a elaboração das faturas teorias destinados a dar à educação o status de prática e arte científicas como já são hoje a medicina e a engenharia. No curso destas considerações, insistimos pela necessidade de demonstração de nossa posição, na analogia entre medicina e educação. Não sirva isto, contudo, para que se pense que a prática educativa possa alcança, a segurança científica da prática médica. Não creio que jamais se chegue a tanto. A situação educativa é muito mais complexa do que a médica. O número de variáveis da primeira ainda é mais vasto do que o da segunda. Embora já haja médicos com o sentimento de que o doente é um todo único e, mais, que esse todo compreende não só o doente,mas o doente e o seu 
"meio", ou o seu "mundo", o que os aproxima dos educadores, a situação educativa ainda é mais permanentemente ampla, envolvendo o indivíduo em sua totalidade, com todas as variáveis dele próprio e de sua história e de sua cultura e da história dessa cultura, e mais as da situação concreta, com os sues contemporâneos e os seus pares, seu professor e sua família. A prática educativa exige que o educador leve em sua conta um tão vasto e disperso grupo de variáveis, que, porvàvelmente, nenhum procedimento científico poderá jamais ser rigorosamente nela aplicado.

Ainda o mais perfeito método de aquisição, digamos, de uma habilidade, não poderá ser aplicado rigidamente. $\mathrm{O}$ educador terá de levar em conta que o aluno não aprende nunca uma habilidade isolada; que, simultâneamente, estará aprendendo outras coisas no gênero de gostos, aversões, desejos, inibições, inabilidades, enfim que tôda a situação é um complexo de "radiações, expansões e contrações" na linguagem de Dewey, não permitindo nem comportamento uniforme nem rígido.

É importante conhecer todos os métodos e recursos já experimentados e provados de ensinar a ler, mas, a sua aplicação envolve tanta cousa a mais, que o mestre, nas situações concretas, é que irá saber até que ponto poderá aplicar o que a ciência lhe recomenda, não no sentido de negá-lo, mas, no sentido de coordenálo e articulá-lo com o outro mundo de fatôres que entram na situação educativa.

Sendo assim, podemos ver quanto a função do educador é mais ampla do que tôda a ciência de que se possa utilizar. É que o processo educativo identifica-se com um processo de vida, não tendo outro fim, como insiste Dewey, sinão o próprio crescimento do indivíduo, entendido êsse crescimento como um acréscimo, um refinamento ou uma modificação no seu comportamento, como ser humano. Em rigor, pois, o processo educativo não pode ter fins elaborados fora dêle próprio. Os seus objetivos se contêm dentro do processo e são êles que o fazem educativo. Não podem, portanto, ser elaborados senão pelas próprias pessoas que participam do processo. O educador, o mestre é uma delas. A sua participação na elaboração dêsses objetivos não é um privilégio, mas a conseqüência de ser, naquele processo educativo, o participante mais experimentado, e, esperemos, mais sábio. Deste modo, a educação não é uma ciência autônoma, pois não existe um conhecimento autônomo de educação, mas é autônoma ela própria, como autônomas são as artes e, sobretudo, as belas artes, uma delas podendo ser, ouso dizer e mesmo pretender - a educação.

A "ciência" da educação, usando o têrmo com tôdas as reservas já referidas será constituída na frase de Dewey, de tôda e qualquer porção de conhecimento científico e seguro que entre no coração, na cabeça e nas mãos dos educadores e, assim assimilada, tome o exercício da função educacional mais esclarecida, mais humana, mais verdadeiramente educativa do que antes.

Os nossos Centros de pesquisas educacionais foram criados para ajudar a aumentar os conhecimentos científicos que assim possam ser utilizados pelos educadores - isto é, pelos mestres, especialistas de educação e administradores educacionais - para melhor realizarem a sua tarefa de guiar a formação humana, na espiral sem fim do seu indefinido desenvolvimento.

O Seminário que ora se encerra foi um primeiro contato entre os professôres e mestres que trabalham nas classes e os que 
trabalham no Centro. Esta aproximação tem um sentido: o de associar à pesquisa educacional o mestre de classe. Na classe é que se realiza a função educativa. E dentro da classe, na cabeça, no coração e nas mãos do aluno. Todo o trabalho do Centro visa, em última análise, tornar mais rica, mais lúcida e mais eficaz essa ação educativa. Nada podemos fazer sem o professor e a pesquisa educacional não pode prescindir do seu concurso.

Se o vosso trabalho se libertar do caráter de trabalho de rotina, de acidente ou de capricho e começardes a registrar por escrito o vosso esfôrço, a manter fichas cumulativas, descritivas e inteligentes, dos alunos, casos-história de experiências educativas, todo êsse material poderá aqui ser estudado, para ver se vos podemos ajudar em vossa tarefa, que continuará autônoma e, além disto, mais consciente, mais controlada e mais susceptível de ser repetida e dêste modo, de se acumular e progredir. Não desejamos tanto ser aqui no Centro um estado-maior a elaborar planos para serem cumpridos por autômatos ou semi-autômatos, mas um grupo de colegas a estudar conosco os problemas escolares, com o objetivo de conseguir conhecimentos para que todo o magistério possa conduzir com mais autonomia a sua grande tarefa. Não teremos regras nem receitas a oferecer, mas buscaremos ajudar-vos no instrumental intelectual indispensável à execução de uma das belas artes e a maior: a de educar.

* Foram mantidas a ortografia e a acentuação gráfica da época.

\section{Notas}

${ }^{1}$ Também o direito não é puramente uma arte formal, mas, não faltam os que o julgam de meramente convencional sinão de arbitrário.

\footnotetext{
Anízio Teixeira

Nascido em Caetité, Bahia, em 1900. Formou-se em Direito pela Universidade do Rio de Janeiro. Em 1924, iniciou sua vida pública como inspetor-geral de ensino da Bahia, onde realizou a reforma da instrução pública. Em 1952, acumulou o cargo anterior com o de diretor-geral do Instituto Nacional de Estudos e Pesquisas Educacionais (Inep) e instituiu o Centro Brasileiro de Pesquisas Educacionais (CBPE). Em 1963, assumiu a reitoria da UnB, após o afastamento de Darcy Ribeiro. Faleceu em 1971, tendo sua candidatura à Academia Brasileira de Letras interrompida.
} 